\title{
Model validation of solar PV plant with hybrid data dynamic simulation based on fast-responding generator method
}

\author{
Dawei Zhao ${ }^{1,2, a}$, Dongping $\mathrm{Hu}^{1}$, Jieqiong $\mathrm{He}^{1}$, Lei Zhang ${ }^{1}$ and Ning Chen ${ }^{1}$ \\ ${ }^{1}$ Renewable Energy Department, China Electric Power Research Institute, Nanjing 210003, China \\ 2 School of Electrical and Electronic Engineering, North China Electric Power University, Beijing 102206, China
}

\begin{abstract}
In recent years, a significant number of large-scale solar photovoltaic (PV) plants have been put into operation or been under planning around the world. The model accuracy of solar PV plant is the key factor to investigate the mutual influences between solar PV plants and a power grid. However, this problem has not been well solved, especially in how to apply the real measurements to validate the models of the solar PV plants. Taking fastresponding generator method as an example, this paper presents a model validation methodology for solar PV plant via the hybrid data dynamic simulation. First, the implementation scheme of hybrid data dynamic simulation suitable for DIgSILENT PowerFactory software is proposed, and then an analysis model of solar PV plant integration based on IEEE 9 system is established. At last, model validation of solar PV plant is achieved by employing hybrid data dynamic simulation. The results illustrate the effectiveness of the proposed method in solar PV plant model validation.
\end{abstract}

\section{Introduction}

With the rapid increase of solar photovoltaic (PV) power integration, its impact on the power grid has received extensive concern and excited wide research interests [1]. The model accuracy of solar PV is the key factor to investigate the mutual influences between it and a power grid. However, this problem has not been well solved. Currently, most research of solar PV model validation is concentrated in solar PV inverter and solar PV unit, and is not enough for solar PV plant or plants.

In recent years, with the wide application of PMU (phasor measurement unit) and WAMS (widearea measurement system), hybrid data dynamic simulation method is proposed and has been successfully applied in synchronous generator model validation, load model validation, and so on [2-4]. Hybrid data dynamic simulation injects external signals to simulation process and opens traditional dynamic simulation loops for interaction with external signals. It is "hybrid" in the sense of bridging the measurement world with the simulation world [3]. Typical data dynamic simulation techniques consist of fast-responding generator method [2-3], phase shifter method [3], variable impedance method [4] and the ideal voltage source method. Among these methods, the fastresponding generator method injects bus voltage and frequency, and it does not require the phase-angle data (for solar PV plants, rare PMU is installed), so it is more suitable for solar PV plant model validation. However, according to the existing literatures, the implementation details of fast-

\footnotetext{
a Corresponding author: zhaodawei $@$ epri.sgcc.com.cn
}

responding generator method and its application in the model validation of renewable energy power plants are all disclosed, this paper will investigate these problems.

\section{Modeling of solar PV plant grid integration system}

A solar PV plant grid integration system is designed in this paper, as shown in Figure 1. The system consists of two synchronous generators and one solar PV plant. In Figure 1, the rated active power of synchronous generator $\mathrm{G} 1$ is $500 \mathrm{MW}$, and this value for $\mathrm{G} 2$ is $700 \mathrm{MW}$. The rate power of solar PV plant is $300 \mathrm{MW}$. The rate active power of Load1 is $300 \mathrm{MW}$, and this value for Load2 is $1100 \mathrm{MW}$.

GE model [5] is used for solar PV plant modeling in this paper, it is realized in DIgSILENT PowerFactory [6] using static generator as interface with the grid, the static generator is a controlled current source, as shown in Figure 2. 


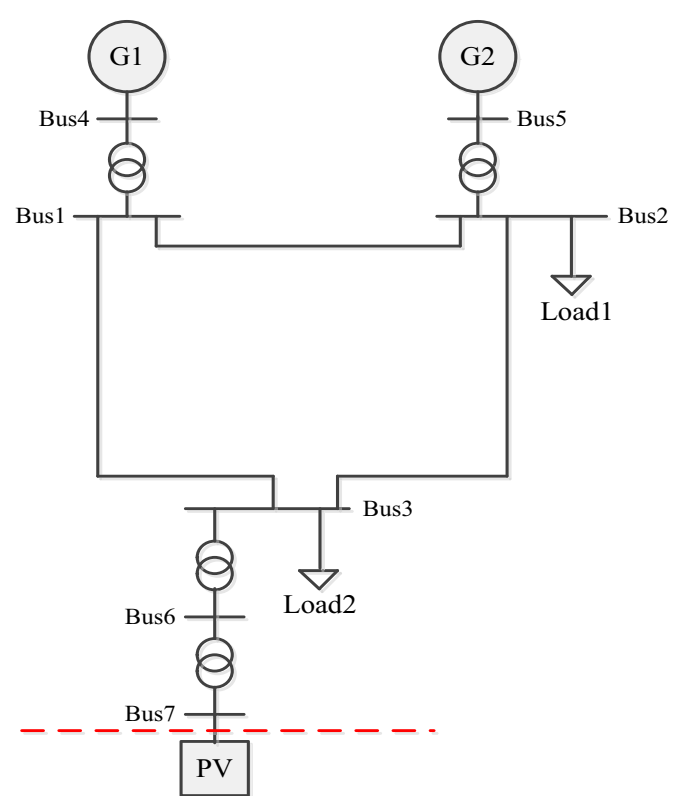

Figure 1. The PV plant grid integration system

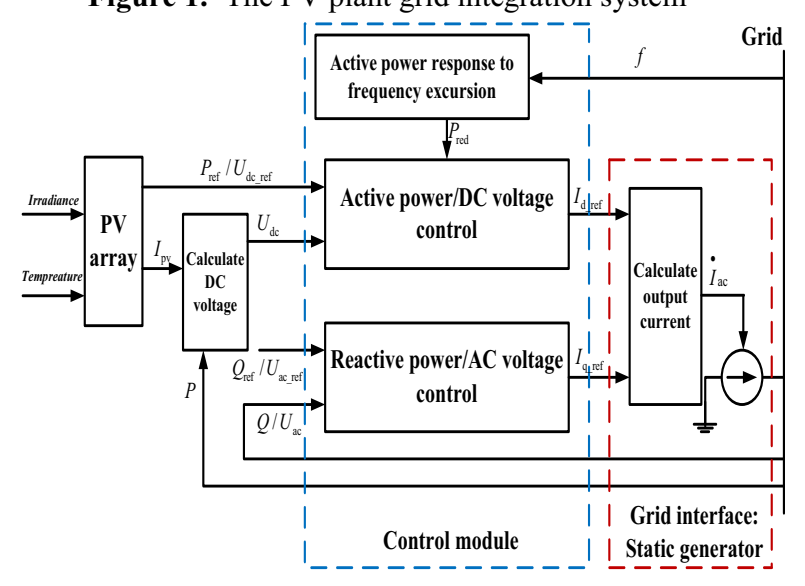

Figure 2. Model structure of PV plant

\section{The hybrid data dynamic simulation method based on fast-responding generator and its realization in DIgSILENT PowerFactory}

A large synchronous generator with a fast responding exciter and governor is used to inject the external signals. From the terminal of solar PV plant, the large synchronous generator can be seen as an equivalent of the rest of power system, as shown in Figure 3. The generator has very small impedance and transient time constants. A known set of signals (voltage, frequency, real power and reactive power) at Bus7 (see Figure 1 and Figure 3) can be obtained easily from regular measurements. Recorded bus voltage and frequency are input as reference values for the generator exciter (EXC) and governor (GOV) respectively [3]. Because of the large size of the generator and fast response controls, simulated bus voltage and frequency are forced to follow very closely the reference values, i.e. measured voltage $\mathrm{V}^{*}$ and frequency $\mathrm{f}^{*}$.

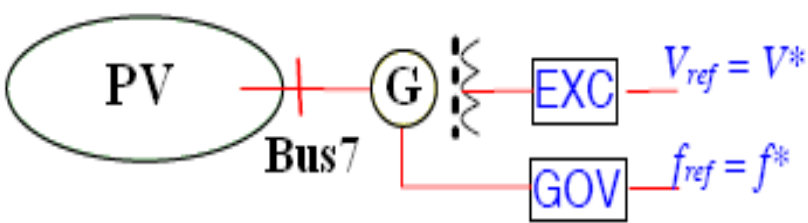

Figure 3. The PV plant grid integration system with a fastresponding generator

The measured values of bus voltage and frequency are all stored in text files, and they can be injected into DIgSILENT PowerFactory software, as shown in Figure 4. In PowerFactory the data can be fed into a generator exciter and governor model using Measurement File (ElmFile) format.

Type1 excitation system (EXC) model and type1 speed governor (GOV) provided by PSASP software [7] are used for synchronous generators in the simulation, the models all have been established in DIgSILENT PowerFactory, and validated by comparing with PSASP [8]. The models of EXC and GOV with injection data are shown in Figure 5.

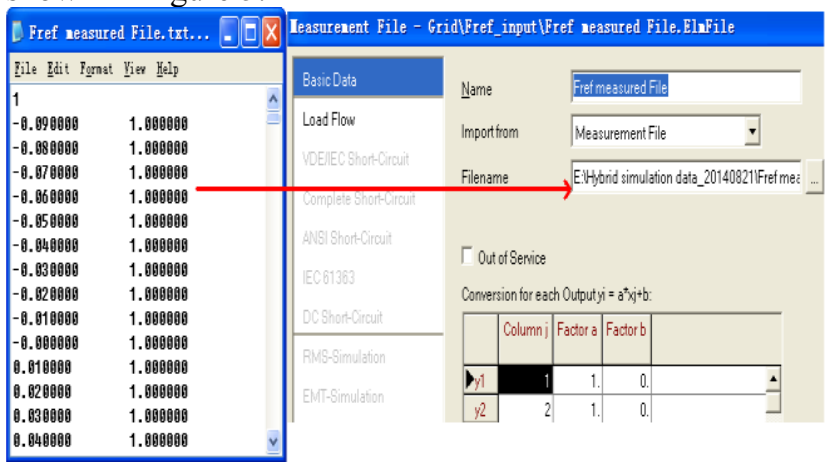

Figure 4. The application of measured frequency's text file in DIgSILENT PowerFactory
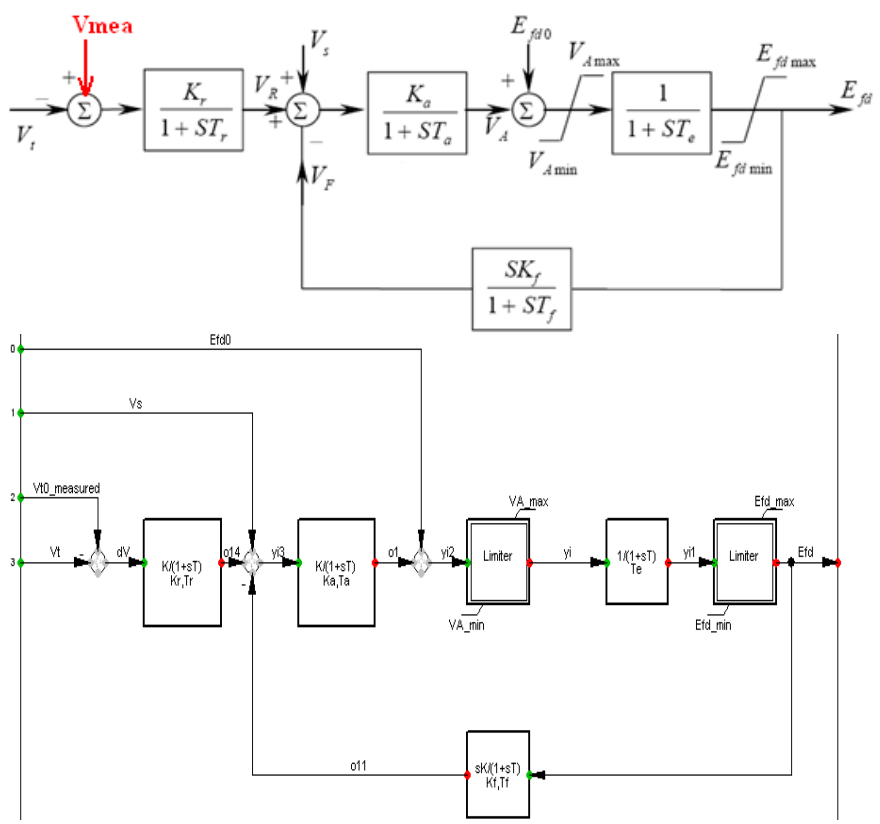

(a) Excitation system 

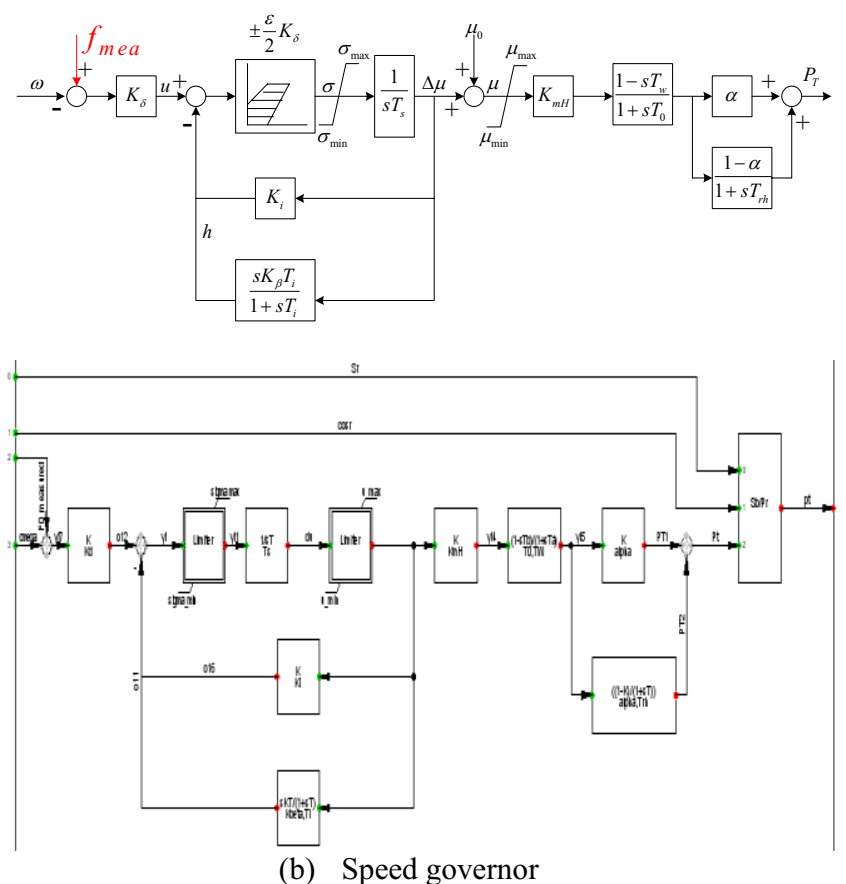

(b) Speed governor

Figure 5. The fast-responding generator's controller realized in DIgSILENT PowerFactory

The parameters of EXC and GOV models used in simulation are listed in Table 1, the time constants are all very small to achieve a rapid control performance. For detailed explanations of the parameters, please refer to [7].

Table 1. The parameters of AVR and PSS models used in

\begin{tabular}{|c|c|c|c|c|}
\hline \multicolumn{2}{|c|}{ EXC } & \multicolumn{3}{c|}{ GOV } \\
\hline $\mathrm{Kr}=1$ & $\mathrm{Kf}=0.04$ & $\mathrm{Kd}=20$ & $\mathrm{~T} 0=0.001$ & $\sigma_{\text {max }}=1$ \\
\hline $\mathrm{Tr}=0.001$ & $\mathrm{Tf}=0.001$ & $\mathrm{~K}_{\mathrm{mH}}=7$ & $\mathrm{Tw}=0$ & $\sigma_{\text {min }=-1}$ \\
\hline $\mathrm{Ka}=50$ & $\mathrm{~V}_{\mathrm{Amax}}=10$ & $\alpha=0.333$ & $K_{\beta}=0$ & $\mu_{\text {max }}=1$ \\
\hline $\mathrm{Ta}=0.001$ & $\mathrm{~V}_{\mathrm{Amin}}=-10$ & $\mathrm{Ki}=0.75$ & $\mathrm{Ti}=0.002$ & $\mu_{\text {min }}=0$ \\
\hline $\mathrm{Te}=0.001$ & $\mathrm{E}_{\mathrm{fdmax}}=5$ & $\mathrm{Ts}=0.001$ & $\mathrm{Trh}=0.002$ & \\
\hline $\mathrm{E}_{\mathrm{fd} \min }=-5$ & & & & \\
\hline
\end{tabular}

\section{Simulation results of solar PV plant model validation}

Suppose that a three-phase symmetrical short-circuit happens on Bus3 (see Figure 1). This fault begins at $3 \mathrm{~s}$ and is cleared at $3.1 \mathrm{~s}$. According to Figure 3, the measured values of Bus7's voltage and frequency are all stored and injected into PowerFactory as reference values. The comparison between simulation outputs and reference values under this scenario is described in Figure 6.
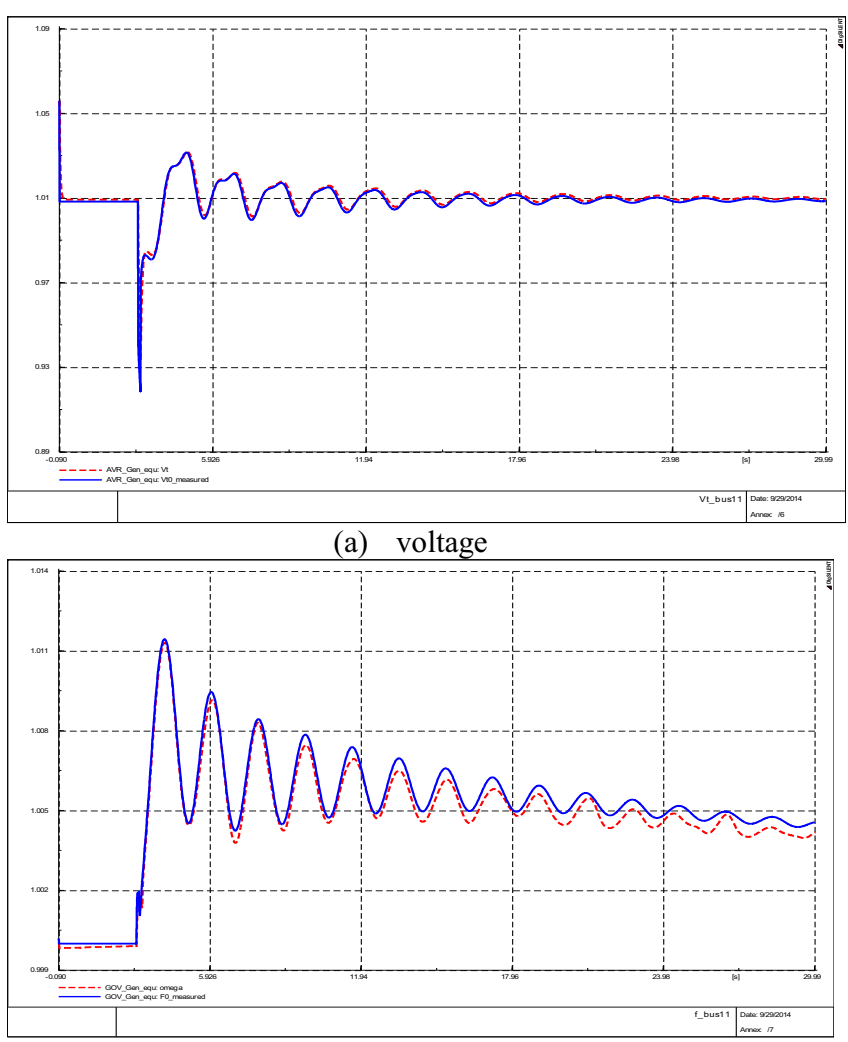

(b) frequency

Figure 6. The comparison between simulation outputs and reference values

The difference between simulation outputs and reference values is acceptable. Then, we can compare the simulated real power and reactive power with the recorded values, if the difference is not small, it demonstrates that PV plant' simulation model or parameter is not accurate enough.

\section{Conclusion}

This paper presents a model validation methodology for solar PV plant via the hybrid data dynamic simulation based on fast-responding generator method. The implementation details of fast-responding generator method are disclosed for the first time. The simulation results illustrate the effectiveness of the proposed method in solar PV plant model validation.

\section{Acknowledgments}

This work is supported by Research Program for youth of China Electric Power Research Institute (Model validation of renewable energy plant using hybrid dynamic simulation method, No. NY84-14-003) and Research Program of State Grid Corporation of China (Renewable power generation performance assessment and fault behavior optimization control technology research and application based on operation data, NY8414-012). 


\section{References}

1. S. Eftekharnejad, V. Vittal, G. T. Heydt, et al, Impact of increased penetration of photovoltaic generation on power systems, IEEE Trans. Power Systems, 28, 2 (2013)893-901

2. D. Kosterev. Hydro turbine-governor model validation in Pacific Northwest. IEEE Trans on Power System s, 19, 2 (2004) 1144-1149

3. Z. Huang, D. Kosterev, R. Guttromson, et al. Model validation with hybrid dynamic simulation// Proceedings of the 2006 IEEE Power Engineering Society General Meeting: Vol 2, June 18-22, (2006) Montreal, Canada

4. J. Ma, D. Han, W. Sheng, et al. Wide area measurements-based model validation and its application. IET Gener. , Transm. , Distrib. ,2, 6 (2008) 906-916

5. K. Clark, N. W. Miller, and R. Walling, Modeling of GE Solar photovoltaic plants for grid studies, Version 1.1, April 16, (2010)

6. DIgSILENT GmbH, Gomaringen, Germany. DIgSILENT PowerFactory manual version 15.1. (2013)

7. China Electric Power Research Institute, Power System Analysis Software Package (PSASP) user's manual, (2010)

8. D. Zhao, D. Jiang, L. Zhu, et al, Modeling and validation on practical control system of synchronous generator based on PowerFactory, Automation of Electric Power Systems, 38, 23 (2014) 27-32, 45 